\title{
Vertical politics in horizontal policy networks: framework setting as coupling arrangement
}

\author{
Joop Koppenjan ${ }^{1}$, Mirjam Kars, Haiko van der Voort \\ Published in: Policy Studies Journal, Vol 37, nr 4, November 2009, pp 769-793
}

\begin{abstract}
Horizontal governance arrangements potentially conflict with the very principles of the representative democracy and its political institutions. This conflict manifests itself in the interaction between representatives and the executive power: Although the former has the formal power to decide upon policies and to check their implementation, the latter participates in horizontal networks and therefore has more resources to influence the content, evolvement and outcomes of the policy process. This erodes the power position of representatives. Framework setting is commonly suggested as an arrangement for representatives to enhance their grip on policy processes. The authors of this contribution examine the effects of framework setting as coupling mechanism between horizontal networks and vertical politics in six policy processes in a Dutch province. Based on network theory and research findings they suggest redefining the concept of framework setting in order to make it more attuned to the complex, interdependent and dynamic nature of policy-making in networks.
\end{abstract}

Keywords: governance, networks, representative democracy, framework setting

\section{Introduction. Horizontal governance in a representative democracy}

Both in the public-administration literature and in policy practice, terms like 'policy networks' and 'governance' are in vogue (Hirst, 2000; Hajer et al., 2003; Soerensen and Torfing, 2006). They reflect the insight that the processes by which public policy is made and is implemented evolve in horizontal settings: complex sets of interactions between mutually dependent but relatively autonomous public, private and societal parties. These networks cut across existing territorial, administrative and functional boundaries (Castells, 1996; Rhodes, 1997, 2000; Kickert, Klijn and Koppenjan, 1997). Steering in such policy networks is referred to as 'governance' (Kooiman, 1993; Pierre, 2000).

From a democratic point of view, these developments are viewed with concern (Ripley and Franklin, 1987; Rosenau, 1995, 2000; Rhodes, 1997, 2000; Marin and Mayntz, 1991). Horizontal governance arrangements potentially conflict with the very principles of the representative democracy and, likewise, with the existing political institutions. According to these principles power within a political community is exercised by elected administrators, mandated by the electorate, who publicly account for the way they carry out that mandate to the electorate. Power is perceived here as the capacity to take authoritative decisions and to ensure their implementation (Dryzek, 2006; Soerensen and Torfing, 2006).

\footnotetext{
${ }^{1}$ J.F.M. Koppenjan, Faculty of Social Science, Erasmus University Rotterdam, P.O.Box 1738, 3000 DR Rotterdam, the Netherlands, email address: koppenjan@fsw.eur.nl
} 
The institutional design of the representative democracy consists of a vertical chain of representation, steering and accountability relations between the electors and the elected, the representatives and political authorities (administrators) and political authorities and civil servants (executive agencies) respectively. Here, political primacy emphasizes the principalagent relations between political authorities and civil servants on the one hand and representatives and political authorities on the other hand (Strom, 2000; Hupe, 2004; Bovens, n.a.).

The rise of policy networks and governance weakens this vertical chain of representation, steering and accountability relations. As Bovens et al. (1995) pointed out some time ago, this leads to 'the shifting of politics': key societal decisions are increasingly taken outside the influence domain of the vertical steering and accountability relations of representative democracy (see also Held, 1995; Thomassen and Schmidt, 1999; Dryzek, 1996; Van Kersbergen and Van Waarden, 2004). In addition to decreased steering possibilities, there is an increase in asymmetry in relations between representatives and executive power as regards the available information, knowledge, expertise and capacity (Scharpf, 1999). As a result, representatives find it difficult to influence the substance and implementation of policy (Klijn and Koppenjan, 2000).

One can conclude that the practices of horizontal governance and vertical politics have their own rationale and that their couplings are weak and problematic. The possibilities for elected politicians in the 'vertical chain' to influence the activities and performance of parties involved in horizontal governance processes and to ascertain accountability are limited. And, the other way around, for horizontal governance it is hard to generate political support and trust and to prevent disturbing interventions from the vertical chain.

As an attempt to strengthen the position of representative bodies, recently, the Dutch government introduced a dual system in local and provincial politics. In this system representatives have got a 'framework setting role', which formally implies that 'the representative body lays down beforehand what the aims and the desired societal effects of a particular policy should be. The Executive sees to the implementation of the policy within the scope of these frameworks' (Association of Provincial Authorities and Ministry of the Interior, 2006). This idea of framework setting builds on notions like 'management by objectives', 'performance management', and 'frame-legislation' (Johnson, 1991; Osborne and Gaebler, 1992; Behn and Kant, 1999; Osborne and Plastrik, 2000; Pollitt, 2003; Bovaird and Löffler, 2003; De Bruijn, 2007).

In this article we examine whether and how 'framework setting' helps to improve the coupling between horizontal governance and vertical politics by enhancing the ability for elected representatives to govern the process of policy making. In the next section we discuss three reactions to the problematic coupling between horizontal governance and vertical politics and position 'framework setting' as a possible solution within this debate. Inspired by policy network theory, we identify three challenges that framework setting in networks should deal with. Section 2 ends with a detailed explanation of our research question and research strategy. Then, in section 3, we report on six case studies into framework setting in the Dutch province of North Brabant, in which we examined whether framework setting contributed to an improved coupling, by analyzing the way the province face the three challenges. In section 4 , we discuss how framework setting could be adapted in order to meet these challenges. Section 5 contains a conclusion.

\section{Vertical politics, horizontal governance, and framework setting}


Both in policy practice and in the public-administration literature, attempts have been made to find a solution for the problematic relation between horizontal governance forms and vertical institutions of representative democracy.

\section{Three reactions to the problematic coupling}

Roughly speaking, three reactions to the problematic coupling between horizontal governance and vertical politics can be distinguished.

Reaction I. Restoring political primacy. The first reaction is that of the call for restoring political primacy, recapturing the public domain. This reaction comprises on the one hand proposals to bridge the gap between electors and the elected by, for instance, changing the electoral system or introducing referendums. On the other hand, this reaction involves proposals to reverse horizontalization by weeding the forest of horizontal relations, streamlining procedures, decreasing the density of administration, halting hiving-off and privatization and reversing them where possible (Lazare, 1996; Mulgan, 2000; Van Kersbergen and Van Waarden, 2004).

Reaction II. Democratizing horizontal governance. The second reaction is based on the assumption that, in a complex society, horizontal forms of administration are inevitable. The aim is then to improve the democratic functioning of these horizontal forms of administration (Soerensen and Torfing, 2006). Improvements are sought in:

- The effectiveness, quality and inclusiveness of the policy performance. Horizontal steering arrangements can lead to policy outcomes that take a wider range of societal values into account than the results of vertical steering (Koppenjan and Klijn, 2004; Soerensen and Torfing, 2006).

- Improving the conditions (including transparency, accessibility, representativeness and accountability) that influence the quality of policy argumentations and performance in horizontal interaction processes within network settings ('deliberative democracy') (Forester, 1989; Hajer and Wagenaar, 2003; Van Kersbergen and Van Waarden, 2004).

- Developing forms of horizontal accountability such as benchmarking, certification, societal reports, self-evaluations, peer-group assessments, assessments by users and stakeholders (Hirst, 1994; 2000; Soerensen and Torfing, 2006).

Reaction III Improving the coupling between vertical democracy and horizontal governance. The third reaction assumes the side-by-side existence of horizontal forms of administration and the vertical institutions of the representative democracy (Weiss, 1998; Pollit, 2003; Klijn and Sketcher, 2007). The key question then is how the coupling between them can be improved (cf., Klijn and Koppenjan, 2000).

A poor coupling between the two practices may limit or reduce the assets of horizontal forms of administration, for example if politicians lay down over-stringent preconditions or if their interventions hamper the cooperation between horizontal partners. Poor couplings also occur when representatives prove unable to act as countervailing power vis-à-vis administrators, civil servants and their horizontal partners. In that case, interference from the vertical chain will be unable to correct the democratic imperfections of horizontal governance (Przeworski et al., 1999; Aucoin and Heintzman, 2000).

Adequate couplings allow representative bodies to steer and to ascertain accountability, while providing implementing bodies with the necessary discretionary room, resources and mandates to operate effectively in network situations. 
In 2002 and 2003, the dual system was introduced in respectively the Dutch local and provincial politics following a change in the Local Government Act and the Provinces Act. In the former situation, members of the Executive were part of the Council and tasks and responsibilities were not clearly separated. The core of the dualization was the 'unbundling' of the Council and the Executive. ${ }^{2}$ This implied that a separation was made in the composition, functions and powers of the Council and the Executive (Ministry of the Interior, 2003). The Executive deals with administration. The Council represents the citizens, sets the frameworks within which the Executive operates, and calls it to account for its performance. Dualization would enhance the transparency of the administrative relations and strengthen the position of the representative body towards the executive board. The introduction of the dual system in local and provincial politics may be seen as a reaction to the problematic relation between vertical politics and horizontal governance.

The solution is sought by clearly separating 'business-like' administration from the 'political' activities of steering and monitoring (Scheltema, 1982; Stout, 1994). The administration deals with the development and implementation of policy in the administrative networks in which other governments, executive agencies, private organizations, interest groups, and citizens may participate. The representative body fulfills a 'framework-setting role' towards the administration (Association of Provincial Authorities and Ministry of the Interior, 2006). The Council does not fulfill this role by supervising all the decisions of the Executive, since it does not have the expertise and the resources to do so, but by making meta-decisions: setting policy objectives, allocating responsibilities and providing broad guidelines for behaviour (compare O’Toole, 1988; Grantham, 2001).

These meta-decisions make up the policy framework, within which boundaries the Executive is supposed to operate and that provides the Executive with the necessary descretionary freedom to interact with network partners and deal with uncertainties during policy implementation. The policy framework also focusses the process by which the Council monitors the Executive and calls it to account (Ministry of the Interior, 2003; Association of Provincial Authorities and Ministry of the Interior, 2006).

An important instrument for the representative body for framework setting is the development of (framework setting) policy white papers, in which the steering and monitoring role of the representative body can be described (Koppenjan et al., 2006: 5).

Figure 1 visualizes the process of framework setting. The horizontal line represents the process of policy making and implementation in which the Executive interacts with the other parties of the network. After policy preparation, the Council decides upon the policy framework. During policy implementation the Council monitors deviations (policy as realized) from the framework (policy as planned) and makes agreements with the Executive on adjusting the implementation in order to comply with the framework.

\footnotetext{
${ }^{2}$ The definitions of the term 'dual system' and the implications of the introduction of such a system can differ from one country to a next. In this article, we refer to the Dutch situation, where dualization implies a division between politics and administration.
} 


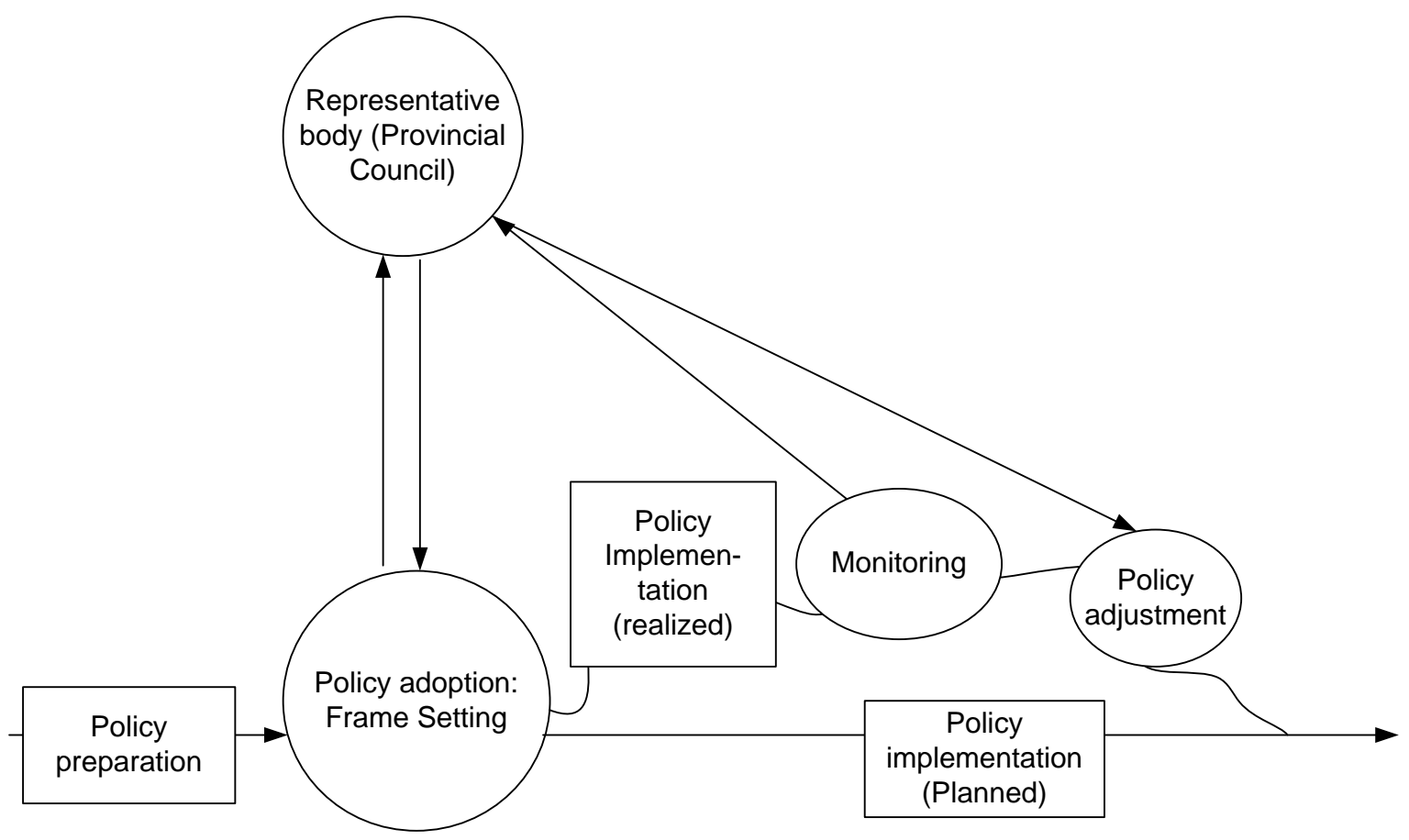

Figure 1. Framework setting by the PC in Dutch provincial policy making

\section{Three challenges for framework setting in policy networks}

There are reasons to question the feasibility of the ideas on dualization and framework setting. First, information on performance often is not used in decision making processess. Furthermore, since frameworks not only constraint the discretionary powers of the administrators and civil servants, but also bind the elected representatives, frameworks may become instruments of the first to reduce the power of the latter (Pollit, 2006).

More feasibility issues arise if we wonder how framework setting relates to the network setting in which administrators and civil servants operate. Reasoning from a policy network perspective, one may expect that framework setting by representative bodies in network settings, as foreseen in the Dutch dualization policy, will not be without problems. Tensions exist between the demands made by the complexity, interdependencies and dynamic of horizontal implementation situations and the characteristics of framework setting as discussed above. We explain these tensions below.

Complexity. Policy networks are characterized by complexity due to the number and pluriformity of actors involved and the complicated nature of the set of issues they deal with. Knowledge is often dispersed over various actors within and outside government. Elected representatives have a hard time to cope with this complexity, due to their limited resources. With regard to the policy topics under discussion, it is just as difficult for them to take good implementation decisions as it is to take decisions about frameworks. Here, too, restrictions exist, such as lack of information, expertise and resources. A major problem is to distinguish between 'political' meta decisions and administrative decisions. With a limited knowledge of a policy problem, how can you decide what the essentials of the policy are? In addition, laying down policy performance in frameworks has its disadvantages. Policy performance is difficult to define and quantify. Quality is hard to capture in specified goals and quantitative indicators. Fixating on concrete aims may cause particular tasks to be neglected or prevent implementers from making adequate trade-offs between divergent or conflicting policy 
requirements on the basis of their professionalism and their tacit knowledge (Johnson, 1991; Roe, 1994; Kelly, 1998; De Bruijn, 2007).

Interdependencies. Administrators are strongly dependent on other parties for the formation and implementation of policy. Policy frameworks have to offer them a certain amount of policy freedom to draft policy in co-production with these parties (compare Hjern and Porter, 1981; O’Toole, 1988; Mazmanian and Sabatier, 1981). The question is whether ex ante formulated frameworks offer the required discretionary freedom and flexibility for this ('t Hart, 2004). Furthermore, administrators run the risk of being held accountable for policy outcomes, for which they are dependent on other parties.

Dynamics. Laying down frameworks ex ante for a longer period insufficiently takes account of the fact that all kinds of developments may occur during the implementation process. These may be market developments, emergence of new resources, new ideas, new political preferences or changes in the policies of higher governments (Kingdon, 1984; De Bruijn and Ten Heuvelhof, 2008; Klijn and Koppenjan, 2004). The static character of frameworks will inhibit administrators to be responsive to these developments. Furthermore, if actors involved in policy processes acknowledge these dynamics, static frameworks will easily become too rigid to be authoritative in debates.

These tensions indicate that framework setting is not automatically effective in horizontal governance. Its effectiveness will largely depend on the way representatives and administrators deal with the tensions between framework setting on the one hand and the complexity, interdependencies and dynamic that mark horizontal governance on the other hand. In this contribution we therefore examine how actors deal with these tensions and what we can learn from that regarding framework setting.

\section{Research Question and Research Strategy: Examining framework setting in the Dutch Province North Brabant}

In this article, we examine, in line with the third reaction discussed in section 2.1, aimed at improving the coupling between vertical democracy and horizontal governance, whether framework setting improves the coupling between horizontal governance and vertical politics and how this relationship is influenced by the way the tensions between framework setting and the characteristics of horizontal governance are dealt with.

This is an intriguing and relevant question, because framework setting as developed in the Dutch dualization policy, might also be seen as a hierarchical principle, an instrument to control network processes, aimed at restoring the primacy of politics (reaction 1). If so, we might indeed expect the tensions between framework setting and the characteristics of horizontal governance to become manifest. Whether framework setting will contribute to linking up vertical democracy with horizontal governance, in line with the ambitions of reaction 3, will depend on the way representatives and administrators apply it in practice. This arouses curiosity as to the policy practice.

In 2005, the province of North Brabant commissioned a study into the conditions that a framework- setting policy white paper should meet, in order to enable the Provincial Council (PC) to steer and monitor adequately, while allowing the Provincial Executive the appropriate 
room to realize its executive tasks. ${ }^{3}$ Apparently, in provincial practice, it proved to be far from easy to work out the framework-setting role of the PC. This study allowed us to examine our research question in the provincial policy practice. ${ }^{4}$

We considered the provincial practice suited for this research, since the policy processes at the level of provinces are pre-eminently examples of horizontal governance and network management. This is due to the fact that provinces in the Netherlands are a government layer between national government and lower governments (municipalities and regional authorities) with many coordination tasks vis-à-vis other governments and with relatively few formal powers. Their functioning and performance is heavily dependent on the collaboration of other actors.

We examined the practice of framework setting in policy networks by analyzing the content of six so-called 'framework-setting policy white papers' of the province of North Brabant, and the policy processes by which they were drafted, adopted and implemented. The policy networks consist of the actors participating in these procesess: members of the PE, civil servants, the staff of executive agencies, other governments, business, special interest groups, citizens, etcetera).

We elaborated our general research question into the following more specific questions:

- What did the framework of a framework-setting policy white paper exactly consist of?

- What role did the PC play in developing, adopting and implementing these white papers?

- To what extent were the tensions between framework setting on the one hand and the complexities, interdependencies and dynamics of the networks involved on the other hand manifest and how did that influence the quality of steering and monitoring by the $P C$ ?

- What can be concluded from this analysis as regards the conditions that should be set on framework-setting white papers and the way framework setting is applied in network settings?

The study into the provincial policy practice was conducted in four steps.

The first step involved the selection of six framework-setting white papers to be studied. As stated in section 2.2, framework-setting white papers are an important instrument in the hands of the PC to realize its framework-setting role. Framework-setting white papers differ from other white papers and policy documents in that they outline the overall policy goals of the province regarding a certain policy area during a number of years (nevertheless,

\footnotetext{
${ }^{3}$ The Dutch provincial government constitutes a government layer in between the national government and lower governments. The Netherlands are divided into twelve provinces. The provincial government consists of a Provincial Council (PC) and the Provincial Executive (PE). The members of the PC are elected once every four years directly by the inhabitants of the province that are entitled to vote. They are member of political parties. A coalition of political parties that has the majority in the PC forms the PE. The governor of the Queen, who is appointed by central government, chairs the PE. The PE has an obligation to inform the PC about the contents of the policies. The PC has the power to enforce resignation of a PE-member by questioning their trust in this member.

${ }^{3}$ The 'Steering with frameworks' study (Koppenjan et al., 2006) was commissioned by the Policy Evaluation Commission of the Provincial Council of North Brabant and was conducted by staff of the Faculty of Technology, Policy and Management of Delft University of Technology from March until September 2006.

${ }^{4}$ The 'Steering with frameworks' study (Koppenjan et al., 2006) was commissioned by the Policy Evaluation Commission of the Provincial Council of North Brabant and was conducted by staff of the Faculty of Technology, Policy and Management of Delft University of Technology from March until September 2006.
} 
for convenience, we'll call them just 'white papers' from now on). Since the status of policy white papers is not always clear, we asked the office of the PC to list white papers that were considered by both PC and PE to be frame setting, given their significance for the policy area involved. From this list we have selected six white papers for in depth analysis. We have tried to make a representative selection by seeking variety in the period covered by the framework, the nature of policy areas involved, and the degree to which the province has autonomy in the respective policy areas. Table 1 shows an overview of the selected white papers.

Table 1. The six framework-setting white papers

Memorandum Substance

Dynamiek en Vernieuwing- De kracht van Brabant ("Dynamic and innovation - Brabant's strength"). Framework Memorandum on Socio-economic Policy 2002-2006. 5 February 2002.

Reconstructie aan zet (“Reconstruction’s turn”). Umbrella memorandum on the Reconstruction of High-intensity Areas. 26 June 2001.

Cultuur in uitvoering (“Culture in progress"). Points of departure for the implementation of provincial cultural policy 2005-2008, 9 September 2003

Kadernota 2005 (“Framework Memorandum 2005”), April 2005.

Meer Samen, Samen meer, Programma BrabantStad 2004-2008 ("More together, together more.

BrabantCity- Program 2004-2008”. 27 April 2004.
The memorandum presents the views of and efforts made in economic policy during the period from 2002 to 2006. The memorandum's mission is: 'The sustainable strengthening of the competitiveness of the business community in an international perspective so as to promote the wealth and well-being of the people of Brabant and a sustainable development, also on a global level' (p. 18).

The memorandum follows the "High-intensity areas (Reconstruction) Act", enacted by the Lower House of Parliament in late 2000. This act was framed in response to the 1997 swine fever epidemic. Reconstructing of rural areas was believed to be a proper response. Reconstruction commissions were to draw up plans for each geographical area. The memorandum sets out what the province expects of these commissions in the next twelve years. Formulated aims relate to the situation that must have been reached not later than 10 years after the adoption of the plans.

The memorandum outlines a framework for the implementation of the provincial cultural policy. The mission is: "To promote the broadest and most active participation possible of the residents of North Brabant in a diverse and high-quality cultural life in their province.” (p.5).

The Framework Memorandum is 'the most important document in the dual planning and control cycle: the document on the basis of which the Provincial Council can make a comprehensive assessment of the policy proposals for the next few years' (p. 3). The memorandum contains a set of proposals for the second half of the administrative period, 2005-2007.

The program is a joint memorandum of the Municipal Executives of the cities of Breda, Eindhoven, Helmond, 's Hertogenbosch and Tilburg and the PE of the Province of North Brabant. The aim of the memorandum is 'To achieve sustainable growth of the quality of life in the urban BrabantCity"BrabantStad" network in economic, spatial, social and cultural respects' (p. 9). 
Provinciaal Verkeer- en Vervoersplan; PVVP+.("Provincial Traffic and Transport Plan; PTTP+”), 3 November 2006.
The memorandum implements the national Transport Mobility Memorandum and the Spatial Planning Memorandum. The memorandum presents a vision of transport mobility in the province for the next 15 years. Its point of departure is the 'door-to-door'approach, meeting individual transport mobility needs of citizens and industry.

Step two consisted of the analysis of the content of the white papers and the processes by which they were drafted, adopted and monitored during implementation. Besides doing a content analysis of the white papers involved, we studied related policy documents and we conducted a total of 18 interviews with Councilors, members of the PE, the staff of executive agencies and target groups.

Step three was the organization of a validating workshop, in which 18 Councilors were given the opportunity to reflect on their steering and monitoring role during the process of development, adoption and implementation of white papers.

Finally, in step four, we formulated recommendations for improving the way the PC sets frameworks and deals with these frameworks.

In the next section the empirical findings of our study are presented: an overview of the practice of framework setting in the province of North Brabant.

\section{Framework setting in North Brabant: findings}

\section{Framework setting in North Brabant}

The practice of framework setting in the province of North Brabant illustrates the difficulties that the apparently simple principle of framework setting involves in practice. We will first discuss the content of the white papers, specifying the nature of the framework they comprise. Then the processes in which the frameworks were drafted, adopted and monitored during implementation will be addressed.

The framework in the white paper. One of the premises behind framework setting is that the frameworks are guiding for the implementation, while they may also have a supporting role for the monitoring and adjusting by the PC. The frameworks studied provided that support, but only to a limited extent. We found a number of aspects compromising the potential of frameworks for these aims.

A first observation is that there was confusion in the provincial practice about what framework setting exactly means. First of all, there were differences in terminology. Dynamic and Innovation was a 'framework white paper', Reconstruction's Turn was an 'umbrella memorandum', the BrabantCity Program was a 'Program' or 'stimulation framework' and Culture in Progress was called 'points of departure for implementation'. It was not always clear where the terminologies originated from and whether they indicated differences between the frameworks.

There were also differences in form between the frameworks studied. Most framesetting white papers set out important substantive priorities and described what parties play an important role and how they are involved in the policy. Many white papers also contained an overview of the instruments with which the province can steer and the resources that can be 
allocated for it. Differences existed particularly in the way the process of monitoring and adjusting by the PC is organized. Such a process has been set out in only two cases (Reconstruction's Turn and PTTP+). The other four white papers did not contain any information about the role of the Provincial Council.

Furthermore, most white papers appeared to have multiple functions, apart from being a steering and monitoring instrument for the PC. They may also have had an information function for both PC and PE, integrating present and future policies in a policy area. They often had a more external function too. Some frameworks have rather been developed for steering and monitoring of implementing bodies and target groups by the PE.

A final conclusion from the analysis is that, although most frameworks contained long lists of points of departure, goals, instruments, resources and projects, they rarely contained quantitative statements about goal achievement. Goals and performance were hardly specified or quantified. In so far as policy indicators have been included, no standard was provided for them, for example in the form of an output obligation. The white papers thus offered many data, but hardly provided support for the specific fulfillment of the PC's monitoring, steering and adjusting role.

Agenda-setting and the preparation process of the framework. Since the PC aims to use white papers as instrument to shape its framework-setting role in the policy process, one would expect the PC to take the lead and to be actively involved in the preparation of these policy documents. In practice almost all white papers have been prepared predominantly at civilservice level. In some cases the PC did play a significant role in these process phases. As regards Reconstruction's Turn, the PC broadened the agenda together with municipalities concerned, supplementing the technical subjects mentioned in the drafts of the white paper with socio-economic issues. This intervention determined the reconstruction process and its outcomes to a great extent. For the Framework Memorandum 2005, the PC itself drew up the agenda, after which civil servants elaborated the proposed subjects.

In the other frameworks under study, the PC, however, played a rather modest role. The framework- setting part of PTTP+ is presented as 'from the PC', but not all respondents recognized a difference between that part and another part, written by civil servants. The other four frameworks were both initiated and prepared by civil servants. The PC joined the process just before the framework was adopted.

During the workshop, Councilors pointed out that they play a reactive rather than a pro-active role in the drafting of policy white papers and therefore hardly have any steering influence. They find it difficult to keep track of the various policy processes and the various documents that policy processes generate. Councilors simply lack the time to familiarize themselves with the complex subject matter. The frameworks have already been developed to a very advanced stage before the PC can study them. This gives Councilors the impression that many documents catch the PC unawares. During the workshop, there proved to be confusion about the status of white papers and the place of the white papers in the policy process. Councilors thus lack insight into the steering and monitoring moments available to them. This is especially so if a white paper cuts across several policy sectors, as was the case in the BrabantCity-Program and Reconstruction's Turn..

A frequently heard complaint concerned 'information overload'. Councilors work part-time and so have limited time and resources to handle information. This information, however, is produced by a civil service consisting of many full-time employees. Moreover, different dossiers often show direct and indirect linkages with each other, suggesting that councilors shouldn't limit themselves to read information strictly addressed to their own dossiers.

Finally, it appeared during the workshop that there is little system in the contacts with 
citizens. As regards many cases, such as Culture in Progress and Dynamic and Innovation, it was found that Councilors have few contacts with executive organizations, target groups and citizens, although these actors do interact intensively with civil servants and administrators. This led to the question from a Councilor in the workshop what the PC can actually still add to a framework that is developed in close interaction between the Executive and other provincial actors.

The adoption of the framework. The PC occasionally played an important role in the decision making on the white papers. We mention two examples of steering in this policy phase:

- The PC did not adopt the white paper Culture in Progress, developed at civil-service level, until a forthcoming change of administration. This enabled the PC to discuss the content for the next administrative period and get the results of that discussion incorporated in the coalition agreement of the PE for this upcoming period. This guaranteed administrative 'commitment' to a number of subjects the PC considered to be important. Besides, a specific subject that was considered important at the time could be included in the framework.

- The PC adopted the Dynamic and Innovation white paper without committing itself to the extra expenditure it requested. During the debate in the Council meeting on the white paper, it was suggested that the decision on this expenditure should be postponed to the debate about the program budget and the annual accounts. The Councilors wanted a substantive debate about the policy, apart from the money. Moreover, they did not want the integral decision making on provincial funds in the context of the Planning and Control cycle to be constrained by earlier financial pledges.

In the other cases the white papers at issue were strongly debated, but this rarely led to substantial amendments. As far as motions and amendments were tabled, according to our respondents they had hardly any steering effect. This picture is confirmed by the cases involving the BrabantCity ${ }^{5}$ partnership. There was much debate about the vagueness of the role of the PC and the province in BrabantCity. However, eventually no solution was found and the framework was adopted. During the workshop, it emerged that the PC occasionally interfered with details rather than essentials of a policy problem or solution. The cause was believed to be the PC's difficulty to have an overall view of the policy. The information overload was also mentioned in this context. White papers were said to be already shaped in detail before the PC gave its comments. At that point most of the important subjects had already been decided upon.

The implementation of the framework. During the implementation of Reconstruction's Turn the PC played an important moderating role in monitoring. This white paper set out a process in which spatial reconstruction commissions (comprising stakeholders from the field) had to submit substantive reconstruction proposals within provincial frameworks. The PC played a role in the composition of the commissions, in solving a conflict with an interest group within the commissions and in dealing with differences between the framework and the commissions' recommendations. The PC also held a substantive debate about the tension between the commissions' proposals for land use and 'vulnerable provincial interests'.

In the other dossiers, however, the monitoring role of the PC appeared to be limited. In as far as agreements were included in frameworks about information supply to the PC, for

\footnotetext{
5 "BrabantCity" is a partnership between the province and five big cities in the province of Brabant. This partnership plays a role in several framework setting white papers, including, of course, the "BrabantCity" Program' we studied.
} 
example in the form of a section about monitoring, these were not always put into practice during the implementation. In the Culture in Progress file, the PC demanded implementation Programs. In the white paper, twelve of such Programs were announced. Only two have actually been issued. The question is whether the PC would then hold the PE to the agreement. In many instances, political rationality prevents the PC from doing so. Loyalty of the large political parties within the PC to the governing coalition may overrule the interest of a firm stand of the PC as an institution.

Besides this political rationale, other factors are at play. In the case of Culture in Progress, respondents said they did not remember the pledge of the implementation Programs. Evidently, not all Councilors had sufficient insight into the overall process in which a framework had been drafted, adopted and implemented. For example, not everybody knew whether any pledges were made during earlier policy phases, what they were and whether pledges were honored. In many cases, they referred to the Registry as a suitable actor to deal with this lack of institutional memory. However, the Registry has only limited resources.

Finally, in all cases studied, the PC was faced with a lack of insight into the extent of goal achievement. The respondents mentioned several causes:

- Complexity (Reconstruction's Turn)

- High abstraction level of the framework (Dynamic and Innovation; Culture in Progress)

- Vagueness about the role of the PC (BrabantCity-Program)

- Too many indicators, without specified target values and norms (PTTP+)

- A lack of reference to the performance of the preceding year (Framework Memorandum 2005)

Remarkably, in the case of Dynamic and Innovation a deliberate choice was made to formulate activities rather than measurable indicators. The reason was that the Executive refused to commit itself to measurable indicators, because too many external factors would influence policy outcomes. A score on measurable indicators would therefore not automatically indicate performance. The formulated activities, however, proved to offer insufficient possibilities for the PC to check whether aims had been achieved.

\section{Analysis: The relation with complexity, interdependence and dynamics}

In recent years, the PC of the province of North Brabant has been looking for a format for its framework-setting role and a way of using framework-setting policy white papers as an instrument in the process. This proved to be a laborious search and the framework-setting role has not taken full shape yet, as shown here in this North Brabant case study. But why is it so difficult? We suggest this is due to the tensions between the nature of framework setting and the characteristics of horizontal policy networks in which policies are developed and implemented. In this section we confront the empirical material we found with the three theoretical tensions between framework setting and policy networks:

\section{Framework setting and complexity.}

- Because of complexity, Councilors had no influence on listing white papers on the agenda and developing them. Policy white papers were prepared at civil-service level on the initiative of the Provincial Executive It was therefore hard for Councilors to gain insight into the preparation of the framework and have steering influence on this development process. This resulted in an information disadvantage at an early stage.

- Complexity caused Councilors to have difficulty in formulating frameworks. Since Councilors were only involved in the development process to a very limited extent, they 
- Complexity led to a limited insight into steering and monitoring moments. The analysis showed that policy white papers were not isolated documents, but that they were interrelated with other documents, frameworks and processes. For example, the three white papers PTTP+, Dynamic and Innovation and BrabantCity frequently referred to each other. This made the process of steering and monitoring an intricate one. What does adopting one framework imply for other frameworks? What frameworks are relevant to concrete issues? What framework should have priority? The PC only had a limited insight into the steering and monitoring moments available to it. Besides, there was confusion about what frameworks and framework-setting white papers actually were.

\section{Framework setting and interdependencies.}

- Interdependencies gave Councilors a disadvantage. Many of the policy white papers were developed in close interaction between civil servants and the PE on the one hand and the field on the other hand. Councilors had far less contact with stakeholder organizations, and had so more incidentally. This also strengthened the Councilors' information disadvantage. Besides, the involvement of the field had a strongly legitimizing function. During the workshop, Councilors wondered aloud what the PC in its representative role could add.

- Interdependencies led to vague frameworks. The frameworks in the white papers we studied were rather abstract and vague and left the PE considerable latitude. Although some white papers, such as the PTTP+, contained performance indicators, they did not contain norms. As we mentioned in section 3.1, the Dynamic and Innovation white paper explicitly opted for the formulation of activities rather than measurable success indicators. The reason was that civil servants and the Provincial Executive felt that external factors influenced performance. It seemed unwise for the Provincial Executive to commit itself to results over which it had no control.

\section{Framework setting and dynamics.}

- Because of dynamics, frameworks did not always succeed in arranging the relation between the PC and the PE. Many white papers paid little attention to the relation between the PC and the PE. This function of framework setting in practice often seems not to have been leading. The frameworks presented in the white papers fulfilled different functions. Some gave an overview of the policy field and the issues at stake (Culture in Progress), some were intended to give the policy a new impulse (Reconstruction's Turn), and some legitimized policy proposals towards the national government (BrabantCity). By presenting frameworks, the province reacted to the dynamics in the arena surrounding provincial and national policy. However, in many cases this was not the function of framework setting as envisaged in the dualistic system.

- Dynamics eroded the relevance of the framework for implementation and monitoring. For instance, during the implementation of the Culture in Progress white paper, it appeared that both implementers and Councilors monitoring the policy had more or less forgotten the content of the white paper after some time. The PC can set requirements on the implementation in white papers, but, evidently, these requirements may lose relevance or authoritativeness in the course of time because of changing circumstances.

\section{Conclusion: why framework setting did not result in an adequate coupling}

Our findings suggest that the present way of dealing with framework setting leads to a non- 
binding coupling between vertical politics and horizontal governance. In fact, the relation between the PC and the PE has hardly been arranged. Examples of this are fatalist attitudes ('no news is good news' about BrabantCity), a lack of institutional memory necessary to confront administrators with pledges made (as was the case for Culture in Progress) and a decoupling of the financial from the substantial debate about a framework (Dynamic and Innovation), which made the latter debate relatively free of obligations. At some occasions the PC succeeded in steering and monitoring the policy process more effectively. This happened for instance when they postponed the adoption of Culture in Progress. Especially in the Reconstruction's Turn- process, the PC succeeded in taking up a constructive role in staffing commissions for operational decision making, mediating between provincial actors and considering 'provincial values' in a debate after reconstruction plans had been made. These actions and interventions have in common that administrators have been left plenty room to maneuver in horizontal networks. None of the actions imply tight frameworks formulated upfront. Still they have had major impact on the outcomes of the public debates.

However, these examples are exceptions. Our findings suggest that usually the PC did not succeed in playing a framework-setting role in provincial policies. It had major problems in taking part in and influencing processes of developing, adopting and implementing frameworks. The PC has not yet developed a clear method for setting frameworks and did not succeed in systematically fulfilling a steering or monitoring role.

A possible policy recommendation might be that framework setting as envisaged in the dual system should be applied far more strictly and consistently. But such advice would ignore our analysis of the tensions between the characteristics of horizontal governance and framework setting. It is precisely the complexity, the interdependencies and the dynamics of horizontal governance that hamper the setting of frameworks or that make frameworks obsolete soon. The observations regarding the absence of tightly formulated frameworks in successful attempts of the PC to influence the policy process, also point in this direction.

So it seems that horizontal networks impede framework setting to be effective if the coupling is arranged like originally foreseen in the dualization policy. For answering the question how this coupling can be arranged so, that the network characteristics are dealt with more adequately, further reflection on the phenomenon of framework setting is needed.

\section{Discussion: rethinking framework setting}

In this section we discuss the implications of our findings for framework setting in policy networks. First we discuss how framework setting might take the complexities, interdependencies and dynamics of networks into account. Next we outline how this type of framework setting would differ from the approach used in the dualization policy. In section 4.3 we show what these thoughts might mean in practice, by presenting our recommendations to the PC of North Brabant.

\section{Aligning framework setting and policy networks}

Building on the theoretical considerations of section 2 and the findings in section 3, we suggest that aligning framework setting with the characteristics of the networks in which policies are developed and implemented, implies dealing with the following issues:

Complexity: Dealing with asymmetry in knowledge and information. The problem of the knowledge disadvantage of the representative body compared to other parties should be dealt 
with. However, the solution of the framework-setting model of the dualization approach, focusing on 'political meta-decisions', is not very satisfactory. In practice it is hard to make distinctions between administrative and political decisions, especially if representatives have limited information on the policy (Przeworski et al., 1999). If policy frameworks are prepared by actors in the policy network, the possibilities of representatives to actually take metadecisions are limited. Moreover, what the meta-decisions regarding a policy are, is not an objective fact, but depends on political judgment. In other words, if representative bodies want to have influence, an early and continuous dialogue is needed between representatives and administrators, in which the first are informed and can determine what they see as the essentials of the policy under discussion.

In doing so, representatives should be prudent regarding the conditions under which they participate in interaction processes with network actors. They should be clear about the role they perform, given their frame-setting task. In this way they prevent wrong expectations of other actors, regarding the possibilities to negotiate outcomes with representatives directly, bypassing the democratic process. Analogous to Jasanoff's proposal to safeguard the impartial position of researchers in the interaction between policy research and policy process, 'boundary work' is required here: arranging interaction moments, with the boundaries between the two domains marked in a way that is clearly recognizable for those involved on the basis of mutually agreed upon and explicit rules and roles that specify different responsibilities and positions of both parties (Jasanoff, 1994).

Interdependencies: Creating conditions for commitment and learning. Framework setting according to the Dutch dualization resulted in a lack of commitment, since the parties feared to be held responsible for policy outcomes, for which they were dependable upon others. Since the process by which members of the Executive were held accountable was not arranged, conditions for commitment and learning were unfavorable (Broadbent et al., 1996; Behn, 2001). If we want to enhance these conditions, the process of holding actors accountable for performance should be organized in such a way that the policy framework is not applied rigidly or at will. We suggest that actors agree upon a loose coupling between performance and implications: thus creating room for debates between representatives and administrators to evaluate outcomes and their causes, and to develop sensible courses of action to deal with deviations of expectations. Tight couplings, which imply that deviations of earlier formulated performance are per definition failures, exclude debate, eliminate learning and result in blame games (De Bruijn, 2007; Hood, 2002).

Dynamics: Dynamizing the process of framework setting. Frameworks should be able to cope with changing circumstances under which policy is drafted and implemented. The framework should be reviewed regularly. The idea that the fate of a policy is determined by crucial 'political meta-decisions' taken at one specific point in time, as the framework setting approach of the Dutch dualization policy seems to suggest, is a far too simplistic view on complex policy processes. Complex interaction processes consist of a series of decisions by which parties gradually develop policy as they go along (Lindblom, 1979; Kingdon, 1984; Teisman and Klijn, 2008). Policy processes are continuous learning processes, in which crucial political decisions continuously present themselves (Roe, 1994; Van Kersbergen and van Waarden, 2004). This insight has drastic consequences for framework setting. There is a need for a more dynamic way of framework setting.

\section{The outlines of framework setting in network conditions}

Building on the considerations in section 4.1, in this section we will outline the characteristics 
of a framework-setting approach that meets the conditions of network settings. We will do this by contrasting this approach with that of the approach suggested in the Dutch dualization policy, which can be characterized as 'ex ante framework setting'.

Ex ante framework setting presupposes a sequential coupling between framework setting and policy process. Frameworks are set beforehand. Policy outcomes are compared with ex ante formulated frameworks, followed by adjustment, if required. Actually, this type of framework setting is aimed at trying to control the process of horizontal governance. Since this does not reflect the actual power relations as existing in the real world, it is no wonder this type of framework setting fails.

If framework setting is aimed at connecting the activities of representative bodies with those of the parties in network settings, we suggest viewing framework setting and policy process as two parallel processes, as visualized in Figure 2.

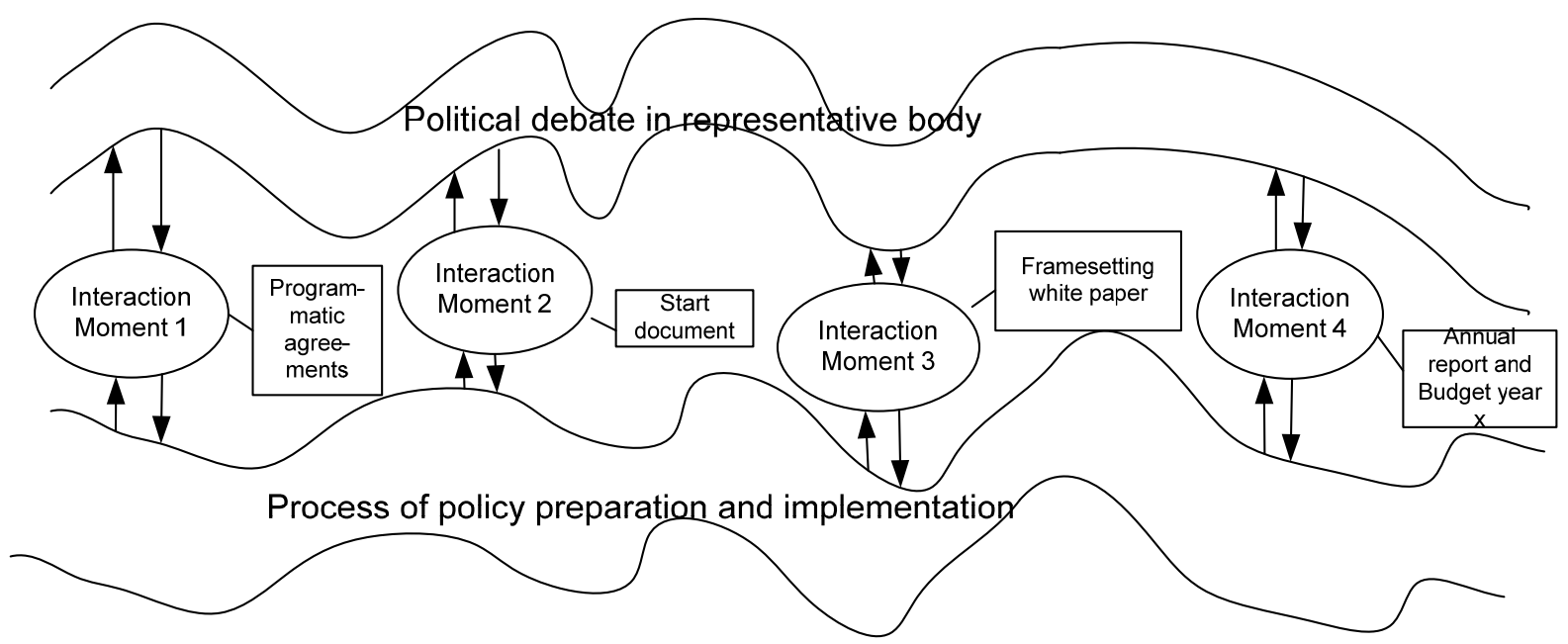

Figure 2. The process of dynamic framework setting

The process of drafting and implementing consists of a series of decisions, a series of policy rounds. During this process, couplings should be made with the political debate conducted or led by the representative body. These couplings imply that representatives are fed by information, proposals and reports from the policy arena at agreed times. In this way the information backlog of representatives is reduced, enabling them to take strategic decisions. In their turn, they take guiding decisions at such times, which are frame-setting for the behavior of administrators in following rounds of interaction in the policy process. Therefore, there is continuous interaction in which political and policy process are mutually adjusted. Table 2 summarizes the main characteristics of this way of frame-setting, by contrasting it with ex ante framework setting.

Table 2. Two approaches to framework setting

\section{Ex ante framework setting}

Framework setting in a horizontal policy network

At a certain point in time 'meta-decisions' are taken that determines policy.

It is possible to distinguish between businesslike administrative decisions and political 'meta- decisions'.
In policy processes, crucial decisions are taken continuously.

It is hard to determine what political 'meta-decisions' are. 
Framework setting aims to reduce the information disadvantage of the representative body as far as this is necessary for taking meta-decisions.

Steering happens beforehand and monitoring and adjusting afterwards.

Unilateral principal-agent relation aimed at controlling the policy process.

Contains an assignment for the executive body about both the policy substance (policy problems, performance) and the policy process (the way the interaction with parties concerned is shaped).

Static: The framework is a fixed, long-time point of reference.
Framework setting aims to improve the information position of representative bodies regarding the policy network during the whole of the process, in line with the limited resources that the representative body has available.

Steering, monitoring and adjusting are ongoing, alternating activities.

Dialogue and mutual learning, recognizing each other's specific roles (boundary work).

Contains agreements with the executive body about both the policy substance and the policy process, including provisions for the interaction with the representative body.

Dynamic: The framework is adapted continuously (but not unconditionally) in interaction with other parties.

Since framework setting has to be realized in network settings, it can not simply be imposed by representative bodies. They have to negotiate this new division of roles and the rules that come with it with the Executive. Since both parties have a common interest in improving the coupling between horizontal governance and vertical politics, in principle it should be possible to arrive at an agreement, although in practice this may prove to be difficult or even impossible. Obviously, the content of framework setting in concrete settings can not be standardized. The characteristics of framework setting we have outlined here are merely general principles to be kept in mind by practitioners, involved in attempts at realizing it. In order to arrive at such a way of framework setting, it is necessary for representative bodies and administrators to internalize these principles.

\section{Recommendations for the implementation of dynamic framework setting in North Brabant}

How might the above suggested ideas be applied in practice? In this section we present the outlines of our advice to the Provincial Council of North Brabant, in order to give an impression.

- Identify interaction moments. Make an agreement with the PE on how intentions to draw up framework-setting memorandums will be placed on the agenda. Informing the PC at an early stage of the administration's intentions to issue memorandums will prevent the PC from being caught by surprise by all kinds of initiatives.

- Specify the nature and content of policy frames. Make an agreement with the PE on what requirements framework-setting memorandums have to satisfy. These requirements concern the substance of the policy, the way the policy is implemented and the way the PE accounts for the policy to the PC.

- Arrange the process of agenda-setting and policy formation. Agree with the PE that an initial memorandum will be issued prior to the framing of a framework-setting policy memorandum. This is a short document setting out the problem as well as the use of, and the need for, the policy. It enables the PC to inform itself in good time and express an opinion about the substance of the policy memorandum and the way it will be realized.

- Arrange the process by which the implementation of the framework is assessed. Make agreements with the Provincial Executive on how, when and in what respects it will 
- Decide upon assessing the practice of framework setting after two years. As PC, lay down the method to be used in framework setting and decide to evaluate this method after approximately two years, because recommendations about other methods will easily remain “paper” (compare O’Toole, 1988).

- Organize self-reflection. Make provisions for moments of reflection at which Councilors contemplate and discuss their new role fulfillment and the appropriate behavior and methods. After all, the ideas about new ways of framework setting will only take root if parties have internalized them, especially because learning experiences regarding framework-setting processes are interrupted by the change of Councilors following elections if no attempts are made to transfer these experiences to newcomers.

Although these proposals for dynamic framework setting imply a radically different way of interaction between Councilors and the Provincial Executive, they do not require revolutionary organizational changes. In the case of the province of North Brabant, numerous provisions for steering and monitoring are already in place. A political-administrative agenda is used by the Council to influence the agenda of the province, framework-setting policy white papers are being drafted and used, a planning and control cycle with a Program budget and an annual report exists, progress reports and evaluations are brought out, etc. What is needed is a new practice in which these instruments are used consciously and systematically to bring about the type of framework setting we propose.

\section{Conclusion}

In this article, we have concluded on the basis of an empiric analysis that ex ante framework setting as defined in the Dutch dualization policy does not contribute to an improved coupling between the vertical institutions of the representative democracy and the practice of horizontal governance. In order for framework setting to do so, it should be aligned with the characteristics of governance in network settings. In the last part of the contribution we outlined the characteristics of such a type of framework setting and made some suggestions regarding its application in practice. Even though they build on findings derived from a Dutch case study, both the case study as well as our reflection were guided by more general theoretical notions. Therefore we think that our ideas on framework setting have a more generic significance that goes beyond the Dutch context. If used prudently, they may help politicians and administrators to reflect on and improve their relationship. The question whether these ideas hold needs to be answered by further systematical testing, both in practice and by empirical research.

We realize that attempts to couple vertical politics and horizontal governance are always vulnerable. The electoral cycle, for instance, a quintessential feature of representative democracy, is an inherent disruption of joint learning experiences regarding the division of roles between representatives and administration. Furthermore, our proposals are at odds with the dominant political culture, which holds incentives for politicians not to have themselves disciplined by agreements with each other and with implementers, and instead cherish the illusion of political primacy.

Although our thoughts on framework setting do not completely solve these problems, they may contribute to the improvement of the coupling between vertical politics and horizontal governance, which to our opinion is essential for both the vitality and relevance of 
the institutions of the representative democracy and the democratic quality of horizontal governance.

\section{References}

Association of Provincial Authorities and the Ministry of the Interior. 2006. Vernieuwingsimpuls Dualisme en provinciale democratie. Available online at http://www.vernieuwingsimpulsprovincies.nl.

Aucoin, P. and R. Heintzman. 2000. "The dialectics of accountability for performance in public management reform.” International Review of Administrative Sciences, 66: 4555.

Behn, R.D. 2001. Rethinking Democratic Accountability. Washington DC: Brookings Institution Press.

Behn, R.D., and P.A. Kant. 1999. "Strategies for avoiding the pitfalls of performance contracting”. Public productivity and management review, 22 (4): 470-489

Bovaird, T., and E. Löffler. 2003. Public management and governance. London: Routledge

Bovens, M.A.P., W. Derksen, W. Witteveen, P. Kalma, and F. Becker. 1995. De verplaatsing van de politiek: Een agenda voor democratische vernieuwing. Amsterdam: Wiardi Beckman Stichting (In Dutch).

Bovens, M.A.P. 2006. Analyzing and Assessing Public Accountability. A Conceptual Framework. European Governance papers. No C-06-01. www.connexnetwork.org/eurogov/pdf/egp-connex-C-06-01.pdf

Broadbent, J., M. Dietrich, and R. Laughlin. 1996. "The Development of Principal-Agent, Contracting and Accountability Relationships in the Public Sector: Conceptual and Cultural problems." Critical Perspectives on Accounting, 7: 259-284.

Bruijn, J.A. de. 2007 ( $2^{\text {nd }}$ ed.). Managing performance in the Public sector. London and New York: Routledge.

Bruijn, J.A. and E.F. ten Heuvelhof. 2008. Management in Networks, On multi-actor decision making. London and New York: Routledge.

Castells, M. 1996. The Rise of the Network Society. Oxford: Blackwell.

Dryzek, J.S. 1996. Democracy in Capitalist Times. Oxford: Oxford University Press.

Dryzek, J.S. 2006. "Networks and Democratic Ideals: Equality, Freedom and Communication.” In E. Soerensen and J. Torfing (eds.). Theories of Democratic Network Governance. Hampshire and New York: Palgrave Macmillan. 262-273.

Forester, J. 1989. Planning in the Face of Power. Berkeley: California Press.

Frissen, P.H.A. 1999. Politics, governance and technology: A postmodern narrative on the virtual state. Cheltenham: Edward Elgar.

Grantham, A. 2001. "How Networks explain unintended Policy Implementation Outcomes: The Case of the UK Rail Privatization.” Public Administration, 79 (4): 851-870.

Hajer, M. and H. Wagenaar (eds.). 2003. Deliberative Policy Analysis. Understanding Governance in the Network Society. Cambridge: Cambridge University Press.

Hart, 't, P. 2004. "Tussen onmacht en overmacht. De rol van de volksvertegenwoordiging bij grote infrastructuurprojecten.” In Grote projecten: inzichten en uitgangspunten (Achtergrondstudies), Tweede Kamer, 2004-2005.” 29283, no. 10 Onderzoek naar Infrastructuurprojecten (In Dutch).

Held, D. 1995. Models of democracy. Cambridge: Polity Press.

Hirst, P. 1994. Associative Democracy. New Forms of Economic and Social Governance, Cambridge: Polity Press. 
Hirst, P. 2000. "Democracy and Governance”. In J. Pierre (ed.). Debating Governance: Authority, Steering and Democracy. Oxford: Polity Press.

Hjern, B. and D. Porter. 1981. "Implementation Structures. A new unit of administrative analysis”. Organization Studies, 2 (3): 211-227.

Hood, C. 2002. “The Risk Game and the Blame Game.” Government and Opposition, 37 (5): $15-37$.

Hupe, P. 2004. Powers behind control: an essay on democracy. Paper presented at the Annual Work Conference of the Netherlands Institute of Government, Rotterdam, October 29, 2004.

Jasanoff, S. 1994. The Fifth Branch. Science Advisers as Policy Makers. Cambridge MA/London: Harvard University Press.

Johnson, H.T. 1991. Relevance lost. The rise and fall of management accounting. Boston, MA: Harvard Business School Press.

Kelly, R.M. 1998. "An inclusive democratic polity, representative bureaucracies and the new public management.” Public Administration Review, 58 (3): 201-208.

Kersbergen, K. van, and F. van Waarden. 2004. "Governance as a bridge between disciplines: Cross-disciplinary inspiration regarding shifts in governance and problems of governability, accountability and legitimacy.” European Journal of Political Research, 43: 143-171.

Kickert, W.J.M., E.H. Klijn, J.F.M. Koppenjan (eds.). 1997. Managing Complex Networks. London: Sage.

Kingdon, J.W. 1995. Agendas, Alternatives and Public Policies. New York: Harper Collins College Publishers.

Klijn, E.H. and J.F.M. Koppenjan. 2000. "Politicians and Interactive Decision Making: Institutional Spoilsports or Playmakers.” Public Administration, 78 (2): 365-388.

Klijn, E.H. and C. Skelcher. 2007. "Democracy and Governance networks: compatible or not?” Public Administration, 85 (3): 587-608.

Kooiman, J. (ed.). 1993. Modern Governance: New Government-Society Interactions. London: Sage.

Koppenjan, J.F.M. and E.H. Klijn. 2004. Managing uncertainties in networks. A network approach to problem solving and decision making. London: Routledge.

Koppenjan, J.F.M, M. Kars, H.G. van der Voort, and E.F. ten Heuvelhof. 2006. Sturen met kaders. Onderzoek in opdracht van de Commissie Beleidsevaluatie van de Provinciale Staten van Noord-Brabant. (Research commissioned by the Committee for Policy Evaluation of the Provincial Council of Noord-Brabant). Delft/Den Bosch (In Dutch).

Lazare, D.F. 1996. The Frozen Republic: How the Constitution is Paralyzing Democracy. New York/San Diego, CA/London: Harcourt Brace.

Lindblom, C.E. 1979. "Still Muddling not yet Through". Public Administration Review, 39 (6): 517-523.

Marin, B. and R. Maynzt. (eds.). 1991. Policy networks: Empirical evidence and theoretical considerations. Colorado: Westview Press.

Mazmanian, D.A. and P.A. Sabatier. 1981. Effective Policy Implementation. Massachusetts: Lexington.

Ministry of the Interior. 2003. Dualisme en provinciale democratie. Integrale tekst Provinciewet vanaf 12 maart 2003. Den Haag: Ministerie van Binnenlandse Zaken en Koninkrijksrelaties, Directoraat-Generaal Openbaar Bestuur, Directie Bestuurlijke en Financiële Organisatie, Afdeling Bestuur en Wetgeving (In Dutch).

Mulgan, R. 2000. “Accountability: An Ever-Expanding Concept?” Public Administration, 78: 555-574.

Osborne, D., and T. Gaebler. 1992. Reinventing government. Reading, MA: Penguin. 
Osborne, D., and P. Plastrik. 2000. The reinventor's fieldbook. Tools for transforming your government. San Francisco, CA: Jossey Bass.

O'Toole, L.J. 1988. "Strategies for Intergovernmental Management: Implementing Programs in Interorganizational Networks.” Journal of Public Administration, 11 (4): 417-441.

Pierre, J. (ed.) 2000. Debating Governance. Authority, Steering and Democracy. Oxford: Oxford University Press.

Pollitt, C. 2003. The essential public manager. London: Open University Press/McGraw-Hill.

Pollit, C. 2006. Performance Information for Democracy, The missing Link? Evaluation, vol 12 (1): 38-55.

Przeworski, A., S.C. Stokes, and B. Manin (eds.). 1999. Democracy, Accountability and Representation. Cambridge: Cambridge University Press.

Rhodes, R.A.W. 1997. Understanding Governance. Policy Networks, Governance, reflexivity and accountability. Buckingham/Philadelphia: Open University Press.

Rhodes, R.A.W. 2000. “Governance and Public Administration.” In J. Pierre (ed.). Debating Governance. Authority, Steering and Democracy. Oxford: Oxford University Press.

Ripley, R.B. and G. Franklin.1987. Congress, the Bureaucracy and Public Policy. Dorsey: Homewood Ill.

Roe, E. 1994. Narrative Policy Analyis: Theory and Practice. Durham, DC: Duke University Press.

Rosenau, J.N. (ed.) 1995. Governance without Government: Order and Change in World Politics. Cambridge: Cambridge University Press.

Roseneau, J.N. 2000. “Change, Complexity and Governance in Globalizing Space.” In J. Pierre (ed.). Debating Governance. Authority, Steering and Democracy. Oxford: Oxford University Press.

Scheltema, M. 1982. “Bestuursrecht: is het bestuur wetgever in eigen zaak?” In W.F. de Gaay Fortman (ed.). Problemen van wetgeving. Deventer: Kluwer (In Dutch). 131-143.

Scharpf, F.W. 1999. Governing in Europe: Effective and Democratic? Oxford: Oxford University Press.

Soerensen, G. 1999. "Sovereignty: Change and Continuity in a Fundamental Institution.” Political Studies, 47 (3): 590-604.

Soerensen, E. and J. Torfing (eds.). 2006. Theories of Democratic Network Governance. Hampshire and New York: Palgrave Macmillan.

Strom, K. 2000. “Delegation and Accountability in Parliamentary Democracies”. European Journal of Political Research, 37: 261-289.

Stout, H. 1994. De Betekenissen van de wet. Amsterdam: University of Amsterdam (In Dutch).

Teisman, G.R. and E.H. Klijn (eds.). 2008. "Special Issue Complexity Theory and Public Management”. Public Management Review, 10 (3): 287-440.

Thomassen, J. and H. Schmidt (eds.). 1999. Political representation and legitimacy in the European Union. Oxford: Oxford University Press.

Van Kersbergen, K. and F. van Waarden. 2004. "Governance as a bridge between disciplines: Cross-disciplinary inspiration regarding shifts in governance and problems of governability, accountability and legitimacy”. European Journal of Political Research, 43: 143-171.

Weiss, L. 1998. The myth of the powerless state. Ithaca, New York: Cornell University Press. 